\title{
Pseudovertical Temperature Profiles Give Insight into Winter Evolution of the Atmospheric Boundary Layer over the McMurdo Dry Valleys of Antarctica
}

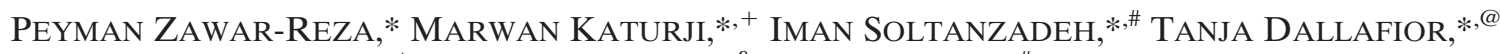 \\ SHIYUAN ZHONG, ${ }^{+}$DANIEl STEINHOFF, ${ }^{\&}$ BRYAN STOREY, ${ }^{\#}$ AND S. CRAIG CARY*** \\ * Centre for Atmospheric Research, University of Canterbury, Christchurch, New Zealand \\ ${ }^{+}$Department of Geography, Michigan State University, East Lansing, Michigan \\ ${ }^{\#}$ Gateway Antarctica, University of Canterbury, Christchurch, New Zealand \\ ${ }^{\circledR}$ Institute for Atmospheric and Climate Science, ETH, Zurich, Switzerland \\ ${ }^{\&}$ Research Applications Laboratory, National Center for Atmospheric Research ${ }^{++}$Boulder, Colorado \\ ** Department of Biological Sciences, University of Waikato, Hamilton, New Zealand
}

(Manuscript received 9 January 2013, in final form 31 March 2013)

\begin{abstract}
Measuring routine vertical profiles of atmospheric temperature is critical in understanding stability and the dynamics of the boundary layer. Routine monitoring in remote areas such as the McMurdo Dry Valleys (MDV) of Antarctica is logistically difficult and expensive. Pseudovertical profiles that were derived from a network of inexpensive ground temperature sensors planted on valley sidewalls (up to $330 \mathrm{~m}$ above valley floor), together with data from a weather station and a numerical weather prediction model, provided a longterm climatological description of the evolution of the winter boundary layer over the MDV. In winter, persistent valley cold pools (VCPs) were common, lasting up to 2 weeks. The VCPs were eroded by warm-air advection from aloft associated with strong winds, increasing the temperature of the valley by as much as $25 \mathrm{~K}$. Pseudovertical datasets as described here can be used for model validation.
\end{abstract}

\section{Introduction}

The McMurdo Dry Valleys (MDVs) are the largest permanently snow/ice-free region in Antarctica. They are a series of glacially excavated valleys located between the Polar Plateau and the Ross Sea (Fig. 1). Characterized as polar desert with average annual precipitation below $50 \mathrm{~mm}$ (water equivalent), this extreme environment lacks vegetation and is deemed to be barren.

The Antarctic winter boundary layer outside of the MDV has been found to be influenced by katabatic and synoptic forcings (Renfrew and Anderson 2006; Parish and Cassano 2001). Knowledge of the MDV boundary layer is still relatively limited. The surface climatological behavior, though, has been studied to some degree in the

\footnotetext{
${ }^{++}$The National Center for Atmospheric Research is sponsored by the National Science Foundation.
}

Corresponding author address: Peyman Zawar-Reza, Dept. of Geography, University of Canterbury, Private Bag 4800, Christchurch 8020, New Zealand.

E-mail: peyman.zawar-reza@canterbury.ac.nz past three decades. In winter, strong wind events affect the climate of the MDV by increasing local air temperatures by as much as $30^{\circ} \mathrm{C}$ (Nylen et al. 2004). It has been estimated that an increase of $1 \%$ in their frequency can increase average winter temperatures by $1^{\circ} \mathrm{C}$. There is also a large spatial variation in the observed warming events-a $14 \%$ increase for every $10 \mathrm{~km}$ up the valley toward the ice sheet (Nylen et al. 2004). The forcing for such events has recently been determined as attributable to the foehn mechanism (Speirs et al. 2010; Steinhoff et al. 2013).

Because of logistical reasons and remoteness, little attention has been paid to the within-valley vertical structure of the boundary layer. A rare glimpse into the vertical stability and structure of the valley atmosphere was provided by McKendry and Lewthwaite (1990; hereinafter ML1990), but for the summertime field season only. Focusing on a limited number of case studies, ML1990 used a combination of radiosondes, pilot balloons, and monostatic acoustic sounding to derive vertical profiles of atmospheric parameters (in the Wright Valley). ML1990 observed that strong downvalley winds (in summer) possessed neutral stability extending to heights of 


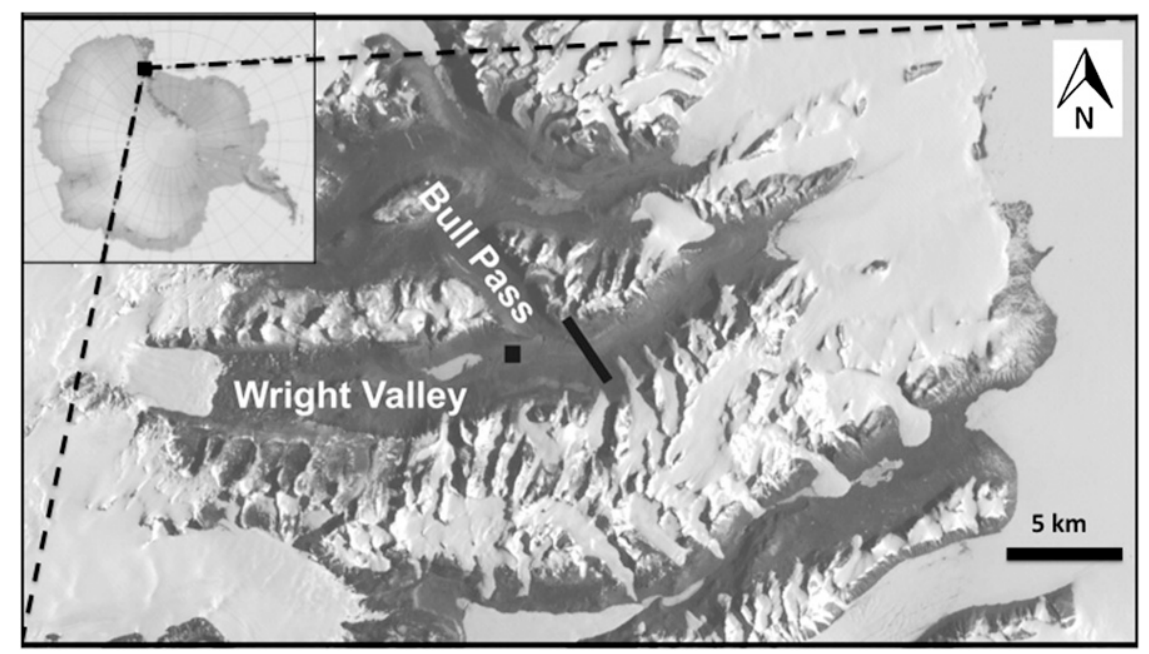

FIG. 1. Map of McMurdo Dry Valleys; the square shows the location of the AWS, and the thick line marks the line where the iButtons transect was installed.

2000-4000 m, but they also measured periods during which stable regimes decoupled the surface-layer air from aloft. There have not been any extensive observational studies of the boundary layer since, and therefore our understanding has not progressed much further.

Here we extend the analysis of ML1990 into winter and to a higher temporal resolution. There is no information available on either the vertical extent of the (stable) boundary layer that can form during synoptically quiescent periods or the thickness of the strong wind intrusions into the valley system climatologically. Data on static stability of the atmosphere not only can guide surface-based meteorological studies but also can provide a good source for validation of numerical modeling research.

Recent studies with atmospheric numerical models, such as the one we used in this study [Polar-Optimized Weather and Research Forecasting (Polar-WRF) model; Hines and Bromwich 2008], have shed light on the strong warming events associated with strong winds and have attributed these events to the foehn mechanism (Steinhoff et al. 2013; Speirs et al. 2010). When compared with in situ surface observations as measured by weather stations, however, the models have difficulty in capturing the onset and cessation of the events or the magnitude of the warming. To understand the shortcomings of model formulations, there is a need for suitable vertical temperature data collected over a long period of time. The extreme nature of the MDV environment has made it extremely difficult to obtain continuous measurements of vertical profiles using either in situ (radiosonde) or remote sensing (radar wind profiler/radio acoustic sounding system) techniques, however.

To alleviate this situation, a few researchers have resorted to using surface-based observations on sloping terrain as a proxy for vertical profiles in remote and harsh environments. To our knowledge, Whiteman et al. (2004) was the first study that pioneered the use of surface-based temperature measurements to derive pseudovertical temperature profiles in the boundary layer. They derived vertical stability by deploying a line of temperature sensors and dataloggers in a valley in the Rocky Mountains. They showed that pseudovertical temperature soundings at night approximated free air temperature over the center of the valley, thereby providing useful insight into nighttime evolution of the boundary layer. Fast et al. (2005) subsequently applied the same reasoning to investigate the nocturnal boundary layer over Phoenix, Arizona. We applied a similar method to derive pseudovertical temperature profiles in the MDV atmosphere, initially for the Wright Valley. We present the first glimpse of the climatological behavior of winter static stability using inexpensive "iButton" miniature temperature sensors as described below.

This paper is the first climatological evaluation of the below-ridgetop behavior of the boundary layer in the Wright Valley for an entire winter through pseudovertical profiling. It shows that pseudovertical profiles are a good proxy for static stability as measured by traditional vertical sounder (such as a radiosonde). The profiles are examined in conjunction with valley bottom meteorological conditions measured by an automatic weather station (AWS), and modeled with Polar-WRF.

\section{Data}

Ground temperature was collected as part of the New Zealand Terrestrial Antarctic Biocomplexity Survey 
(nzTABS; http://nztabs.ictar.aq) research program. The overall aim of nzTABS is to characterize the biophysical drivers (including micrometeorological conditions) that determine the spatial distribution of microbiota. Since there is a distinct link between environmental temperatures and microbial activity, the program employed a vast network of ground-surface and deep temperature measurements (more than 200 sensors) in major tributaries of MDV. Here we focus on data from 14 Maxim Integrated, Inc., Thermochron iButtons (model DS1921G; range from $-40^{\circ}$ to $+85^{\circ} \mathrm{C}$; accuracy of $\pm 1^{\circ} \mathrm{C}$ from $-30^{\circ}$ to $+70^{\circ} \mathrm{C}$ ) positioned on a transect across the Wright Valley just east of Bull Pass (Fig. 1; thick line). The transect was roughly aligned in a north-south direction and was located so that a range of elevations from both north- and south-facing aspects was sampled.

The data used in this work were from a network of sensors buried $2 \mathrm{~cm}$ below the ground to shield them from solar radiative heating; because we have narrowed our analysis to winter, solar radiation is not an issue, however. The sensors were placed on the valley floor and on both the north- and south-facing walls at 30,130, 230 , and $330 \mathrm{~m}$ above valley floor (valley floor is at $170 \mathrm{~m}$ above mean sea level). To ensure the iButtons could be relocated and retrieved, the location of each device was GPS tagged and marked with a bright orange stick. The sensors were retrieved during the next field season, and the data were downloaded and quality controlled. Since each sensor is logging ground temperature every $2 \mathrm{~h}$, a complete annual record is obtained this way at relatively high temporal resolution.

Standard climatological data were also collected continuously near the Bull Pass Hut at $2 \mathrm{~m}$ above the valley floor (Fig. 1), using an AWS assembled from off-the-shelf products from the Onset Corporation. Air temperature was measured by an S-THB-M002 sensor with a full measuring range from $-40^{\circ}$ to $75^{\circ} \mathrm{C}$, where the error increased linearly from \pm 0.2 to 0.7 as temperature decreased from $0^{\circ}$ to $-40^{\circ} \mathrm{C}$. Ground temperature was measured with an S-TMB-M002 sensor with accuracies of $\pm 0.2^{\circ} \mathrm{C}$ suitable for operation in an environment from $-40^{\circ}$ to $100^{\circ} \mathrm{C}$; the ground sensor was planted at $2-\mathrm{cm}$ depth. Wind direction and speed were measured with an S-WCA-M003 sensor, which provided a measuring range of $0-44 \mathrm{~m} \mathrm{~s}^{-1}$.

To check the plausibility of the pseudovertical profiles, a supplemental three-dimensional numerical dataset was prepared for the MDV using the Polar-WRF model. Polar-WRF was initialized with National Centers for Environmental Prediction global reanalysis data and was nudged every $6 \mathrm{~h}$, with grid spacing for nested grids of 36,9 , and $3 \mathrm{~km}$, respectively. For a detailed description of the employed physics options and the treatment of the

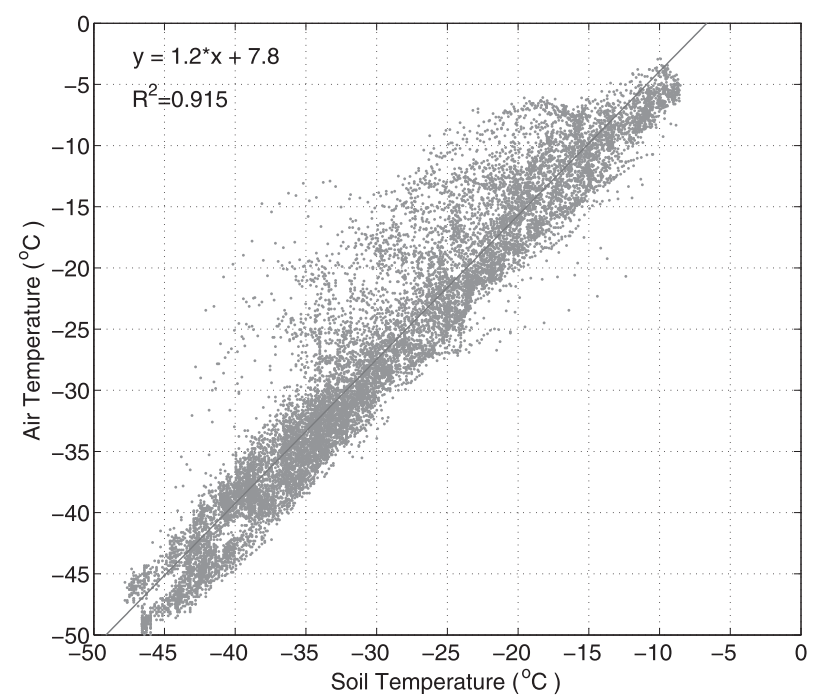

FIG. 2. Scatterplot of hourly air temperature and 2-cm soil temperature as measured by the AWS at Bull Pass (May-October 2011).

land cover and surface schemes, see Soltanzadeh et al. (2012).

\section{Results and discussion}

Earth's ground temperature is tightly coupled to air temperature through surface energy exchanges (Geiger et al. 2009). The temperature of the ground not only continuously responds to air temperature fluctuations but also to surface cover (i.e., vegetation, which is absent in MDV), soil moisture variations, latent energy exchanges, shortwave radiation fluxes near the surface, and intersoil thermal exchanges. The interaction of all of these components determines the temperature of the ground in short and long time scales. Note that the MDV soils are extremely dry (McKay et al. 1998) and that shortwave radiation is totally absent in winter. Ground and air temperature coupling has been investigated extensively, and it has been determined that with minimal surface cover and/or absence of shortwave radiation, which is the case for the MDV, air temperature alone can reproduce the thermal environment of the ground (Beltrami and Kellman 2003).

To understand the magnitude of coupling between the air and ground temperatures, a paired-in-time correlation between the hourly averages of the ground temperature and the air temperature was performed for the Wright Valley AWS (Fig. 2). There was a strong correlation between the two measurements in winter (correlation coefficient squared $R^{2}=0.91$ ), showing that ground temperature was a good predictor and proxy for air temperature at short time scales. Therefore it is safe 

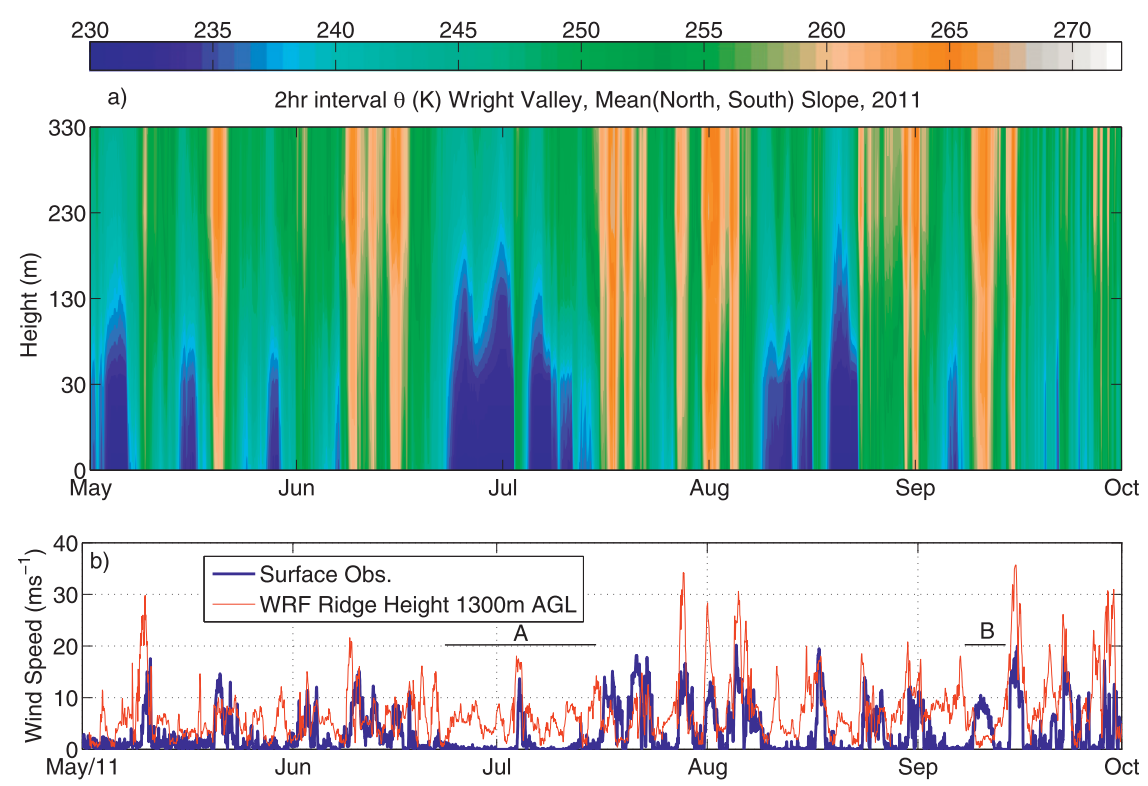

FIG. 3. (a) Time-height cross section of potential temperature (shaded contours), and (b) wind speed time series from the Wright Valley weather station and Polar-WRF.

to assert that the iButton temperature measurements of the ground were a good approximation to air temperature.

Figure 3 illustrates the pseudovertical profiles of potential temperature alongside the 15 -min average surface wind speed from AWS (valley bottom) and Polar-WRF ridgetop ( $1300 \mathrm{~m}$ above ground level) wind speeds at hourly intervals spatially averaged over 5 grid points (from the $3-\mathrm{km}$ grid) around the AWS location. It is immediately apparent that the pseudovertical profiles provided dynamically consistent information about the vertical structure and static stability of the valley boundary layer. There were approximately 10 periods from May to October during which shallow cold pools were established, each associated with stagnant wind speeds at the surface (as measured by the AWS) and very low valley-bottom temperatures $\left(230 \mathrm{~K} ;-43^{\circ} \mathrm{C}\right)$. The ridgetop wind speeds typically did not go above $10 \mathrm{~m} \mathrm{~s}^{-1}$ in these conditions. Orographic trapping of cold air in valleys and basins - valley cold pools (VCPs) occurs frequently during winter and has been observed in many regions around the globe, including the western United States (e.g., Reeves and Stensrud 2009). VCPs are defined as topographically trapped, stagnant air masses that are colder than the air above. Numerical studies have found that the near-ground cooling is due to longwave radiative flux divergence. Vertical advection of temperature, on the other hand, has been found to dominate the cooling process for the upper-basin areas (Katurji and Zhong 2012). The persistence of the cold pool is primarily a function of large-scale flow (Zängl 2003).

The lengths of VCPs in the Wright Valley varied from just over 1 day to as long as 14 days. The longest VCP episode occurred in the latter half of June and stretched well into July and was interrupted once by a strong wind event at the beginning of July (Fig. 3b; episode A). The period was characterized by being very stagnant-wind speeds rarely went above $1 \mathrm{~m} \mathrm{~s}^{-1}$ at the surface and at ridgetop did not exceed $10 \mathrm{~m} \mathrm{~s}^{-1}$. The cold pool was approximately $130 \mathrm{~m}$ thick, and its top seemed to oscillate, probably in response to the interaction of the cold air in the valley with the overlying warm atmosphere above. There was a brief period during which the VCP was broken when both the surface and ridgetop wind speeds exceeded $10 \mathrm{~ms}^{-1}$, leading to the immediate warming of the valley atmosphere from the top. This almost neutrally stratified regime lasted for only 2 days as the strong wind eased off and the cold pool rebuilt. Note that the increase in wind strength at the ridgetop occurred before the surface, mirroring the warming of the pseudovertical temperature from aloft. The strong flow in this case seemed to reach $300 \mathrm{~m}$ above the valley floor, with the dramatic warming most likely associated with the foehn mechanism, for this specific case (Steinhoff et al. 2013).

The VCPs were interspersed with periods of neutral stability (little variation in the vertical gradient of potential temperature), a relatively much warmer boundary layer (approximately by $25 \mathrm{~K}$ ), and higher surface 


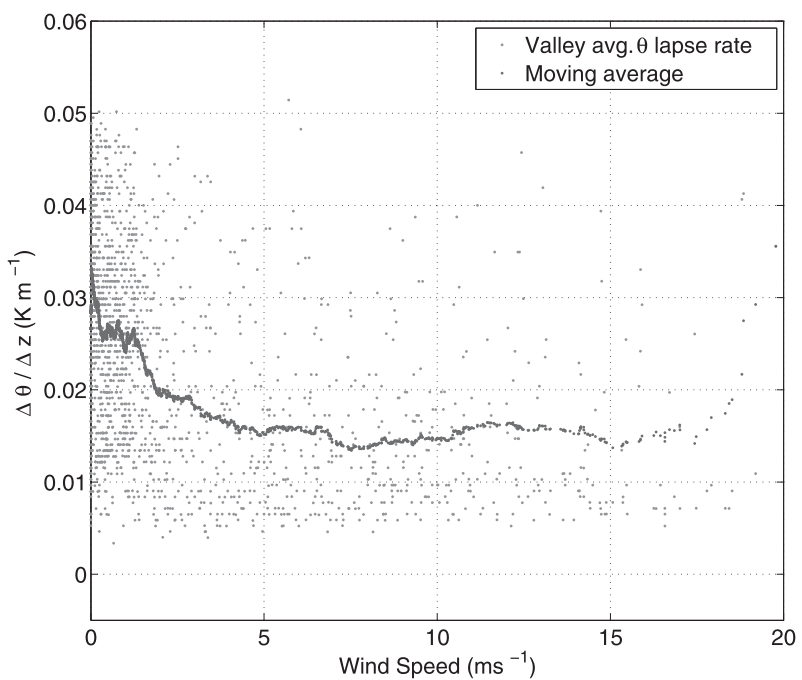

FIG. 4. Scatterplot of vertical gradient of potential temperature against wind speed at valley bottom. The average lapse rate is calculated from averaging the lapse rates between iButton increments (100-m height difference).

and ridgetop wind speeds $\left(>10 \mathrm{~m} \mathrm{~s}^{-1}\right)$. Approximately 15 such episodes have been recorded by the pseudoprofiles, lasting up to 4 days. Periods outside these warm episodes were characterized by gradual reestablishment of VCPs (cold air layers accumulating from below) with varying strengths or by their destruction from aloft probably by turbulent erosion or wave breaking (Steinhoff et al. 2013) (cases in which the ridgetop wind speed was higher than the surface wind speed). It is interesting to note that there were a number of cases in which surface winds were stronger than ridgetop winds (Fig. 3b; episode B). These cases cannot be confidently explained with the given dataset but might fall in any or a combination of the following categories: katabatic flows, lowlevel wave breaking decoupled from ridgetop flow, or simply modeled ridgetop wind speeds that are not correct and for which the model failed to predict the timing of the gravity wave.

To establish a link between surface wind speed and static stability, average vertical gradients in potential temperature were calculated for the entire period of study (Fig. 4). Positive values of the gradient indicated an increase in potential temperature with height-the stable regime, whereas a tendency toward zero indicated neutral conditions. Clearly the high wind speeds tended to produce vertical mixing by being more turbulent, promoting neutral stability. Near-neutral stability existed predominantly for wind speeds above $5 \mathrm{~m} \mathrm{~s}^{-1}$. Below $5 \mathrm{~m} \mathrm{~s}^{-1}$, the stability increased rapidly as wind speed decreased. Of interest is that near-neutral conditions could also exist during stagnant periods. A closer examination of the data reveals that in certain situations most of the boundary layer could be neutral when the cold pool was either forming (from below), or was eroding (from the top), as can happen when strong winds started or stopped flowing into the area. Strong wind speeds at the surface could also be associated with statically stable conditions; this situation might indicate overlying mountain-wave activity.

This is the first time that such a temporally dense, long-term dataset has been obtained from a remote valley system in Antarctica. The pseudovertical profiles alongside Polar-WRF and AWS show that prolonged stagnant conditions in the MDV are frequent and are typically eroded by foehn mechanism from aloft.

\section{Conclusions}

In the MDV, stable layers formed during synoptically quiescent periods, decoupling the surface from the upper atmosphere; these stable and stagnant conditions lasted up to 2 weeks. The inversion depth was variable in time and was linked to ridgetop meteorological conditions. The strong-wind-event intrusions into the valley boundary layer warmed up the entire 300-m-thick layer by as much as $25 \mathrm{~K}$ through the foehn mechanism. This method, incorporated with Polar-WRF data, will be used in future work to construct the distinct thermal and dynamic features of katabatic and foehn events in different McMurdo Dry Valley systems.

Acknowledgments. The authors thank Antarctic New Zealand for providing logistical support for this research. The data were kindly provided by the nzTABS program.

\section{REFERENCES}

Beltrami, H., and L. Kellman, 2003: An examination of short-and long-term air-ground temperature coupling. Global Planet. Change, 38 (3-4), 291-303.

Fast, J. D., J. C. Torcolini, and R. Redman, 2005: Pseudovertical temperature profiles and the urban heat island measured by a temperature datalogger network in Phoenix, Arizona. J. Appl. Meteor., 44, 3-13.

Geiger, R., R. H. Aron, and P. Todhunter, 2009: The Climate near the Ground. Rowman and Littlefield, 584 pp.

Hines, K. M., and D. H. Bromwich, 2008: Development and testing of polar Weather Research and Forecasting (WRF) model. Part I: Greenland ice sheet meteorology. Mon. Wea. Rev., 136, 1971-1989.

Katurji, M., and S. Zhong, 2012: The influence of topography and ambient stability on the characteristics of cold-air pools: A numerical investigation. J. Appl. Meteor. Climatol., 51, 1740-1749.

McKay, C. P., M. T. Mellon, and E. I. Friedmann, 1998: Soil temperatures and stability of ice-cemented ground in the McMurdo Dry Valleys, Antarctica. Antarct. Sci., 10, 31-38. 
McKendry, I., and E. W. D. Lewthwaite, 1990: The vertical structure of summertime local winds in the Wright Valley, Antarctica. Bound.-Layer Meteor., 51, 321-342.

Nylen, T. H., A. G. Fountain, and P. T. Doran, 2004: Climatology of katabatic winds in the McMurdo dry valleys, southern Victoria Land, Antarctica. J. Geophys. Res., 109, D03114, doi:10.1029/ 2003JD003937.

Parish, T. R., and J. J. Cassano, 2001: Forcing of the wintertime Antarctic boundary layer winds from the NCEP-NCAR global reanalysis. J. Appl. Meteor., 40, 810-821.

Reeves, H. D., and D. J. Stensrud, 2009: Synoptic-scale flow and valley cold pool evolution in the western United States. Wea. Forecasting, 24, 1625-1643.

Renfrew, I. A., and P. S. Anderson, 2006: Profiles of katabatic flow in summer and winter over Coats Land, Antarctica. Quart. J. Roy. Meteor. Soc., 132, 779-802.

Soltanzadeh I., P. Zawar-Reza, M. Katurji, and T. Dallafior, 2012: Sensitivity analysis of WRF for the dry valleys, Antarctica under summertime weak pressure gradient conditions. Presentations, Atmospheric Model Parameterizations in the Polar
Regions Workshop, Boulder, CO, International Commission on Polar Meteorology, 15 pp. [Available online at https://ees. kuleuven.be/icpm_workshop2012/presentations/Peyman_Zawar_ Reza_ICMP2012.pdf.]

Speirs, J. C., D. F. Steinhoff, H. A. McGowan, and D. H. Bromwich, 2010: Foehn winds in the McMurdo Dry Valleys, Antarctica: The origin of extreme warming events. J. Climate, 23, 35773598.

Steinhoff, D. F., D. H. Bromwich, and A. Monaghan, 2013: Dynamics of the foehn mechanism in the McMurdo Dry Valleys of Antarctica from Polar WRF. Quart. J. Roy. Meteor. Soc., doi:10.1002/qj.2038, in press.

Whiteman, C. D., S. Eisenbach, B. Pospichal, and R. Steinacker, 2004: Comparison of vertical soundings and sidewall air temperature measurements in a small Alpine basin. J. Appl. Meteor., 43, 1635-1647.

Zängl, G., 2003: The impact of upstream blocking, drainage flow and the geostrophic pressure gradient on the persistence of cold-air pools. Quart. J. Roy. Meteor. Soc., 129, 117-137. 